\title{
TMS Receives AIME Grant; Material Advantage Member Bringing MSE to the Public

\section{themagazine}

\section{member news}

Share the good news about your professional accomplishments! Contact Kaitlin Calva, JOM Magazine Managing Editor, at kcalva@tms. org. Please note that only news submitted by current TMS members will be considered.
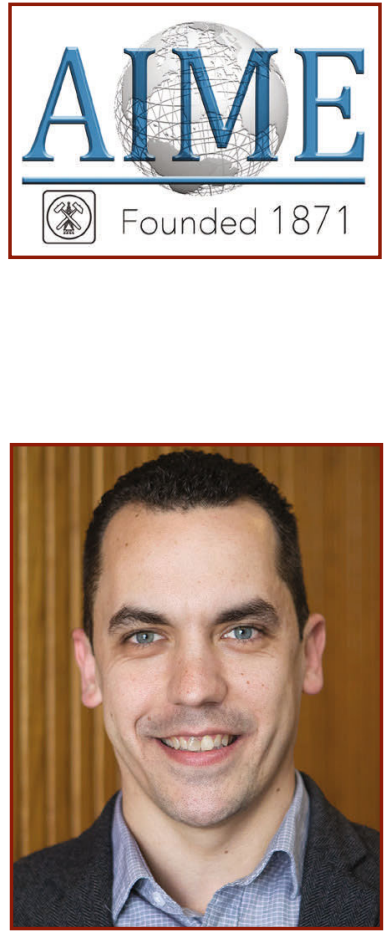

Paul Ohodnicki

\section{AIME Provides Support to TMS and Other Member Societies}

The American Institute of Mining, Metallurgical, and Petroleum Engineers (AIME) approved a \$1 million grant in February 2021 to its member societies, which include TMS, to mitigate the negative impact on society operations associated with the COVID-19 pandemic. AIME's member societies include TMS; the Association for Iron \& Steel Technology (AIST); the Society for Mining, Metallurgy, and Exploration (SME); and the Society of Petroleum Engineers (SPE). The grant will be divided equally among the four groups.

"The COVID-19 pandemic has presented unprecedented challenges to the association community, including the disruption of convening people for knowledge sharing and networking," said George Luxbacher, AIME president. "All have had to pivot to new ways of delivering member value, some requiring significant new resources. AIME hopes that this increased support will ease the transition."

For TMS, delivering member value in the past year has included establishing the COVID-19 Resource Portal, providing meaningful virtual conference experiences, and engaging online professional development courses, and building a robust library of webinars that members can access at no charge.

"This grant will support TMS as we weather disruptions to many of our traditional activities and pivot toward new ways of better serving our members around the world during the pandemic," said James J. Robinson, TMS executive director. "We greatly appreciate the support of AIME in helping us meet these goals. I think it is fitting that, as we celebrate the 150th anniversary year of AIME, we are working together to develop new capabilities that will serve our members far into the future."

The American Institute of Mining, Metallurgical, and Petroleum Engineers was founded in 1871 by 22 mining engineers in Wilkes-Barre, Pennsylvania, USA, and celebrates its 150th anniversary in 2021. TMS will be celebrating the AIME anniversary year at the TMS 2021 Virtual Annual Meeting \& Exhibition, March 15-18, 2021, and at the TMS 2022 Annual Meeting \& Exhibition, February 27-March 3, 2021, in Anaheim, California, USA.

\section{Paul Ohodnicki Receives ARPA-E Grant}

Paul Ohodnicki, associate professor of mechanical engineering and materials science at the University of Pittsburgh (Pitt), received \$1 million from the U.S. Department of Energy's Advanced Research Projects Agency-Energy (ARPA-E) Rapid Encapsulation of Pipelines Avoiding Intensive Replacement program.

Ohodnicki's lab at Pitt will collaborate with other research groups at Pitt and Pacific Northwest National Laboratory on their project, “'Innervated' Pipelines: A New Technology Platform for In-Situ Repair and Embedded Intelligence." The award was announced in November 2020, and work on the project began in January 2021.

The "innervated" pipelines will mimic the nervous system with optical fiber sensor technology embedded into the internal pipelines of critical infrastructure, such as natural gas pipelines. Through the combination of embedded sensors, artificial intelligence, and machine learning, this smart monitoring technology would allow for targeted repair of the "intelligent" pipelines with robotic crawlers, reducing both the time and cost of repairs.

Ohodnicki has been actively involved in several committees since becoming a TMS member in 2009. In 2010, he received the Functional Materials Division (FMD) Young Leaders Professional Development Award. He currently serves on the TMS Board of Directors as FMD Director/Chair. In 2016, he received a Presidential Early Career Award in Science and Engineering from the Department of Energy. And in 2019, his work on cobalt-based nanocrystalline alloys for gapless inductors earned him an R\&D 100 Award. 


\section{Material Advantage Student Launches MSE Podcast}

Material Advantage member Punith Upadhya and co-host Thomas Miller are bringing materials science and engineering (MSE) to a new audience through their podcast, It's a Material World.

The podcast markets itself as "the show that uncovers why materials science will change the world," and it delivers on that promise through a series of episodes with guests who discuss "the secret interactions materials science has in our everyday lives." From using nanotechnology in the fight against COVID-19 to exploring how materials innovations help engineer better clothing, each episode gives listeners a glimpse into some of the ways that materials science influences the world around them.

Upadhya is currently pursuing his M.S. in MSE at Georgia Institute of Technology (Georgia Tech) with a focus on nanomaterials and biomaterials. Miller recently completed his B.S. in MSE at Georgia Tech where his primary interest was in functional materials. The pair conceived the idea for their podcast in the summer of 2020 when their internships transitioned to a virtual environment and were delayed due to COVID-19. They channeled their newfound free time into planning and launching the podcast and the first episodes were posted by August that year.

Miller notes that one goal for the podcast is to highlight MSE "as a lens to look at solutions to some of the biggest problems we're facing right now in the world" and "a discipline uniquely equipped to solve these problems." Upadhya has similar hopes for the podcast showing the general public how "materials science and engineering plays a role in our everyday lives, and how innovations in this field will dramatically change the world." Ultimately, the pair hopes the podcast will also encourage more students to pursue a career in MSE.

It isn't all work, though: both hosts set out to have a good time discussing MSE and their earnest interest in the topics ropes listeners in. "My favorite part about the podcast is the guests we get a chance to talk to," Upadhya says. "Each of our guests have an impressive foundation of knowledge, and we hope their passion for the field resonates with our listeners."

New episodes are uploaded every two weeks and can be accessed on your preferred podcast platform or at https:// link.chtbl.com/ymvMBLjb?sid=tms.

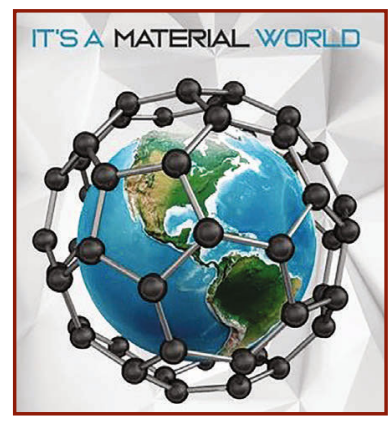

\section{In Memoriam}

TMS extends its condolences to the family, friends, and colleagues of Michael Loretto, emeritus professor at the University of Birmingham, who passed away in January 2021. He received his B.Met. in 1955 from Sheffield University and his D.Sc. in 1972 from the University of Birmingham.

Loretto's career spanned the globe and bridged sectors, as he held positions at the Commonwealth Scientific and Industrial Research Organisation (CSIRO) in Australia, Battelle Memorial Institute in the United States, and the Cavendish Laboratory at the University of Cambridge and the Interdisciplinary Research Centre (IRC) in Materials for High Performance Applications at the University of Birmingham in the United Kingdom. He also published about 300 papers and conference presentations over the course of his career. In 2011, he retired from his role as director of the IRC but remained actively involved in the programs he established while there.

A longtime TMS member, he was recognized at TMS 2014 Annual Meeting \& Exhibition with a special symposium, A Lifetime of Experience with Titanium Alloys: An SMD Symposium in Honor of Jim Williams, Mike Loretto, and Rod Boyer. In 2015, he received the TMS Cyril Stanley Smith Award.

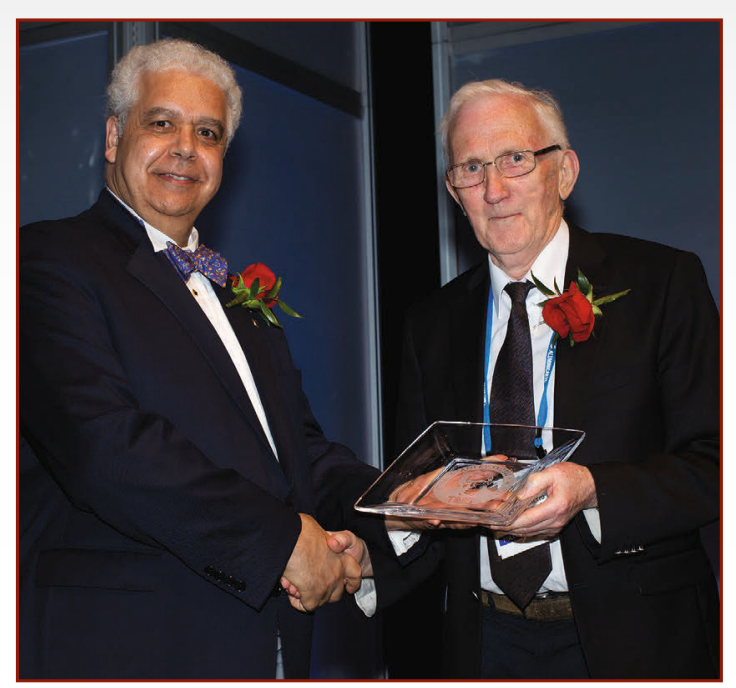

Michael Loretto (right) receives the 2015 Cyril Stanley Smith Award from 2014 TMS President Hani Henein. 